\title{
FK-array response sımulation parameters of the four glacial events in greenland derived from array transfer functions by gpfksımulator (geopsy) software
}

\begin{abstract}
In this study, we have analyzed the four glacial events (Mw 5 and $\mathrm{T}>30 \mathrm{~s}$ ) recorded in Greenland and applied fk-array response simulation to German Regional Seismic Network (GRSN) using array transfer functions of surface waves (Rayleigh) and basic procedure of the array response by Gpfksimulator (GEOPSY) software. This study presents fk-array response results for Greenland updated through 2008. The main processing step used at Gpfksimulator is to attribute waveform patterns to estimate the slowness, azimuth and back-azimuth parameters and to perform event array process. This process analyzes and images the array response simulation to associate seismic phase arrivals to define the four glacial events. Finally, we list the array response simulation parameters of the four events and present array response images regarding the nature of the four glacial earthquakes with GRSN seismic network (GERMAN-GR and GEOFON-GE)
\end{abstract}

\author{
Volume 4 Issue 2 - 2019 \\ MToker,' E Kozlovskaya ${ }^{2}$ \\ 'Department of Geophysical Engineering Yuzuncu Yıl University, \\ Turkey \\ ${ }^{2}$ Laboratory of Applied Seismology, Sodankylä Geophysical \\ Observatory (SGO), University of Oulu, Finland
}

\section{Correspondence: Toker M, PhD, Assistant Professor, Department of Geophysical Engineering, Yuzuncu Yıl University, Zeve Campus, Van, Turkey, Tel 5436247503,}

Email tokermu@gmail.com

Received: July 05, 2018 | Published: March 14, 2019

\section{Introduction}

The largest glacial earthquakes in Greenland generate longperiod $(T>30 \mathrm{~s})$ seismograms and they are similar in amplitude to those generated by a moment-magnitude $M w=5$ tectonic earthquake. ${ }^{1}$ The globally recorded long-period signals from one Greenland event illustrate the large amplitude of the seismic signals even at long distances. ${ }^{1-3}$ The detection of glacial earthquakes followed the development and application of a new algorithm designed to identify seismic sources globally on the basis of their generation of longperiod seismic waves. The algorithm is based on "array-processing techniques". Vertical-component seismograms from the global network of seismic stations are filtered between 35 and $150 \mathrm{~s}$ and phase adjusted to correct for Rayleigh wave propagation delays from a test location to each station. ${ }^{1-4}$ When the location corresponding to a seismic event is found, all the signals will be in phase. This means the alignment of the corrected Rayleigh wave arrivals for one of the detected earthquakes in Greenland. ${ }^{1,2}$ The initial systematic application of the detection algorithm to three years of data (1999-2001) from the Global Seismographic Network (GSN) led to the identification of 46 previously unreported earthquakes of $4.6 \leq M \leq 5.0$ in glaciated areas of Greenland, Alaska, and Antarctica, with 42 of the events located along the eastern and western coasts of Greenland. ${ }^{1-4}$ In addition to their slow character, these earthquakes were shown to generate seismic surface waves that were not well explained by the standard moment-tensor representation of stress release used for tectonic earthquakes. The surface waves were found instead to be well fit by a single-force source model, ${ }^{5}$ which describes the forces acting on the solid earth during a landslide. Fifty-nine earthquakes were detected during 2006-2008; source parameters for these events are listed in Table 1, ${ }^{1,6,7}$ Western Greenland currently generates large numbers of glacial earthquakes: Eleven or more earthquakes have been detected in each of the five most recent years, compared with an average of 4.5 events per year for the same region during the period 1993-2003. ${ }^{1}$ Distinct characteristics of glacial earthquakes $(M \sim 5$ and $T>30 \mathrm{~s})$ motivate the use of long-period surface waves to describe this new class of earthquake model. In this study, we first review the discovery of glacial earthquakes as a seismological phenomenon and discuss the surface wave characteristics of the four detected glacial events with magnitudes; $M=4.9,2007-07-04 ; M=4.8,2007-07-09 ; M=4.7$, 2007-07-09; $M=4.7,2007-07-20$ (Table 1). ${ }^{1}$ We present glacial eventdetection and array processing results for Greenland updated through 2008 and review the evolving understanding of the selected high quality glacial events that have resulted from several investigations of rapidly moving outlet glaciers in Greenland and summarize the basic procedure of the array response simulation for the observations available for study. Finally, we list the array response simulation parameters of the four events and array response images regarding the nature of the four glacial earthquakes with GRSN seismic network (GERMAN-GR and GEOFON-GE) (Figure 1).

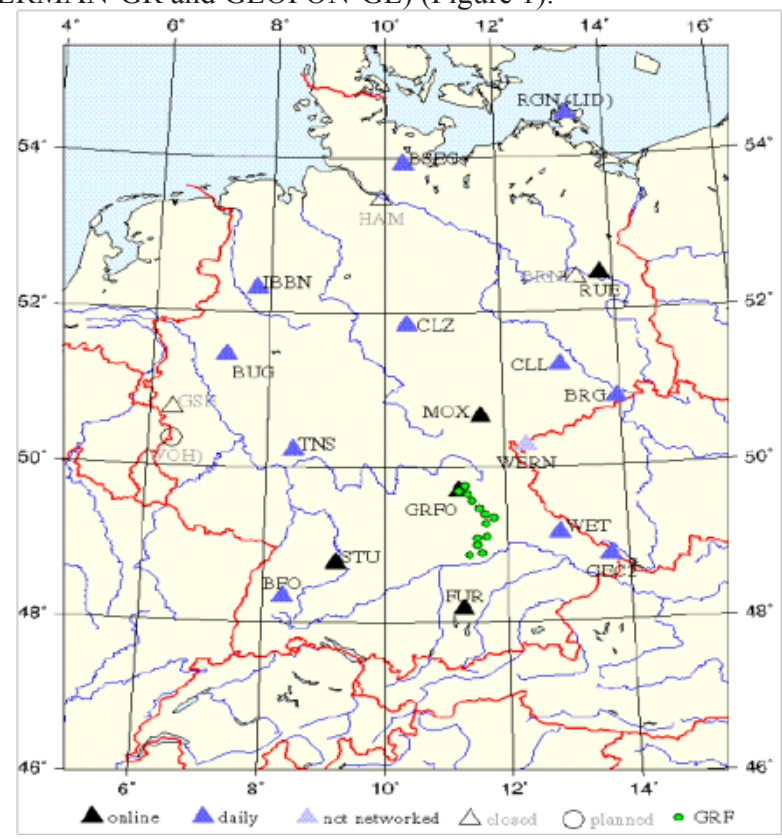

Figure I Map of the station sites of the German Regional Seismic Network (GRSN). 
Table I Source parameters for 59 glacial earthquakes in Greenland

\begin{tabular}{|c|c|c|c|c|c|c|c|c|c|}
\hline Date & Time & Latitude & Longitude & $M$ & Date & Time & Latitude & Longitude & $M$ \\
\hline $2006 / 02 / 13$ & $20: 29: 52$ & 70.25 & -30.75 & $4.8 \mathrm{C}$ & $2007 / 08 / 03$ & $19: 25: 12$ & 72.25 & -52.25 & $4.8 \mathrm{C}$ \\
\hline $2006 / 02 / 28$ & $22: 44: 32$ & 69 & -33 & $4.8 \mathrm{~A}$ & $2007 / 08 / 13$ & $20: 37: 52$ & 66.25 & -38.75 & $4.8 \mathrm{~B}$ \\
\hline $2006 / 03 / 04$ & $23: 05: 20$ & 65.75 & -41.25 & $4.7 \mathrm{~B}$ & $2007 / 08 / 25$ & $9: 19: 04$ & 75.25 & -56.75 & $4.9 \mathrm{~A}$ \\
\hline $2006 / 04 / 29$ & | I:39:12 & 65.25 & -41.25 & $4.8 \mathrm{~B}$ & 2007/09/II & $22: 42: 00$ & 70.25 & -50.75 & $4.6 \mathrm{C}$ \\
\hline 2006/05/0I & $6: 44: 32$ & 72.25 & -52.75 & $4.9 \mathrm{~A}$ & $2007 / 10 / 13$ & $5: 55: 12$ & 74.75 & -56.75 & $4.8 \mathrm{~A}$ \\
\hline $2006 / 06 / 24$ & $10: 48: 32$ & 69.25 & -49.75 & 4.7E & $2007 / I|/ 2|$ & 18:04:56 & 66.25 & -38.75 & $5.0 \mathrm{~A}$ \\
\hline $2006 / 07 / 10$ & 18:13:36 & 65.25 & -40.75 & $4.8 \mathrm{~A}$ & $2007 / I I / 24$ & 0:08:56 & 68.5 & -33.5 & $4.8 \mathrm{~A}$ \\
\hline $2006 / 07 / 16$ & $3: 15: 28$ & 69 & -31 & $4.6 \mathrm{C}$ & $2007 / I I / 24$ & $12: 54: 32$ & 66.5 & -38.5 & $4.9 \mathrm{~A}$ \\
\hline $2006 / 07 / 16$ & $6: 41: 52$ & 73.25 & -53.25 & $4.7 C$ & $2007 / I I / 24$ & |3:29:52 & 67.25 & -38.25 & $4.8 \mathrm{~A}$ \\
\hline $2006 / 07 / 25$ & $4: 51: 44$ & 68.75 & -49.75 & $4.7 C$ & $2007 / 12 / 14$ & $6: 39: 36$ & 75.25 & -56.75 & $4.9 \mathrm{~A}$ \\
\hline $2006 / 08 / 10$ & $18: 45: 20$ & 77.5 & -65.5 & $4.8 \mathrm{~B}$ & $2007 /|2 / 3|$ & $14: 40: 56$ & 66.25 & -38.75 & $4.9 \mathrm{~A}$ \\
\hline $2006 / 08 / 23$ & $17: 19: 28$ & 65.75 & -37.75 & $4.7 C$ & $2008 / 02 / 14$ & $5: 12: 24$ & 72.75 & -55.75 & $4.8 \mathrm{~S}$ \\
\hline $2006 / 08 / 28$ & 7:55:04 & 69.5 & -25.5 & $4.6 \mathrm{~B}$ & $2008 / 04 / 05$ & $21: 06: 08$ & 75.5 & -56.5 & $4.8 \mathrm{~A}$ \\
\hline $2006 / 09 / 10$ & 4:20:16 & 77.75 & -57.25 & $4.9 \mathrm{C}$ & $2008 / 04 / 07$ & 13:58:00 & 74.25 & -56.75 & $4.7 \mathrm{C}$ \\
\hline $2006 / 10 / 09$ & 4:03:12 & 76.5 & -60.5 & $4.8 \mathrm{~B}$ & $2008 / 05 / 04$ & $12: 52: 40$ & 65.5 & $-4 \mid .5$ & $4.8 \mathrm{~B}$ \\
\hline $2006 / 10 / 14$ & $7: 23: 20$ & 76 & -58 & $4.8 \mathrm{~B}$ & $2008 / 05 / 28$ & $21: 06: 40$ & 70.75 & -49.25 & $4.7 \mathrm{~B}$ \\
\hline $2006 / I I / 05$ & $9: 13: 04$ & 75.75 & -58.25 & $4.7 C$ & $2008 / 06 / 12$ & |7:20:08 & 69 & -49 & 4.7E \\
\hline $2006 / I I / 28$ & $10: 55: 44$ & 68.75 & -32.75 & $4.9 \mathrm{~B}$ & $2008 / 06 / 13$ & I5:40:40 & 75.75 & -57.75 & $4.8 \mathrm{C}$ \\
\hline $2006 / 12 / 19$ & $16: 57: 44$ & 74.75 & -57.75 & $4.8 \mathrm{~B}$ & 2008/06/19 & I5:20:00 & 74.75 & -58.25 & $4.8 \mathrm{~B}$ \\
\hline $2007 / 04 / 22$ & $8: 55: 04$ & 66.25 & -38.25 & $4.7 \mathrm{~A}$ & $2008 / 07 / 13$ & $4: 59: 44$ & 69.5 & -49.5 & $4.8 \mathrm{C}$ \\
\hline $2007 / 04 / 23$ & $21: 56: 56$ & 75.25 & -58.25 & $4.8 \mathrm{~A}$ & 2008/08/0I & |4:43:20 & 66.5 & -38.5 & $4.8 \mathrm{~A}$ \\
\hline $2007 / 05 / 30$ & $2: 57: 12$ & 77.5 & -63.5 & $4.7 C$ & 2008/08/0I & $23: 00: 40$ & 66.75 & -39.25 & $4.8 \mathrm{~A}$ \\
\hline $2007 / 06 / 09$ & $5: 16: 56$ & 75.75 & -60.75 & $4.8 \mathrm{~B}$ & $2008 / 08 / 14$ & $20: 58: 24$ & 77.75 & -58.75 & $5.0 \mathrm{~A}$ \\
\hline $2007 / 07 / 04$ & $16: 55: 20$ & 69.25 & -49.75 & $4.9 \mathrm{~A}$ & 2008/08/19 & $21: 05: 28$ & 66.25 & -38.25 & $4.8 \mathrm{~B}$ \\
\hline $2007 / 07 / 09$ & I:08:16 & 66.25 & -37.25 & $4.8 \mathrm{~A}$ & $2008 / 1 / / 03$ & $16: 44: 48$ & 68.75 & -33.75 & $4.9 \mathrm{~B}$ \\
\hline $2007 / 07 / 09$ & $2: 42: 08$ & 66.75 & -38.25 & $4.7 \mathrm{~B}$ & 2008/II/07 & | 3:44:24 & 77.5 & -66.5 & 4.7E \\
\hline $2007 / 07 / 09$ & $5: 31: 12$ & 75 & -57 & $4.6 \mathrm{C}$ & $2008 /|I / 2|$ & $20: 31: 52$ & 76 & -58 & $4.9 \mathrm{~A}$ \\
\hline $2007 / 07 / 20$ & $0: 36: 16$ & 69.25 & -33.25 & $4.7 \mathrm{~A}$ & $2008 / I I / 25$ & $4: 10: 40$ & 68.5 & -33.5 & $4.9 \mathrm{~A}$ \\
\hline $2007 / 07 / 24$ & 23:03:12 & 77.25 & -60.75 & $4.9 \mathrm{~A}$ & $2008 / 12 / 13$ & |4:47:52 & 68 & -34 & $5.0 \mathrm{~A}$ \\
\hline $2007 / 07 / 26$ & $22: 42: 48$ & 66.5 & -38.5 & $4.7 \mathrm{~A}$ & & & & & \\
\hline
\end{tabular}

${ }^{a}$ Origin times and epicenters for 59 glacial earthquakes in Greenland, 2006-2008. The letter code following the magnitude $M$ indicates the quality of the detection and location: $A$ is the highest quality and $C / E$ is the lowest, , ,6,7

\section{Theory}

We use German Regional Seismic Network (GRSN) in the processing of data from the large regional GERMAN (GR) and GEOFON (GE) array. Figure 1 shows the configuration of the GERMAN array and the layout of the seismometer sites for the regional arrays. The German Regional Seismic Network (GRSN) (Figure 1) is comprised of 16 STS2 digital broadband stations with a flat, velocity-proportional response characteristic in the frequency range $8.33 \mathrm{mHz}$ to $40 \mathrm{~Hz}$. Besides monitoring and collecting highquality data from regional and global seismic events, it is specifically aimed at recording and locating all events with $M L>2$ on German territory. All stations are continuously recorded and, with one exception, connected via Internet with each other and with the network center at the Gräfenberg Observatory (GRFO) in Erlangen. The latter is also the center for the Gräfenberg broadband array (GRF). Five stations transmit their data to Erlangen in real time while the other networked stations automatically send data once a day at fixed times during the night or, in case of special events, on request by dialing-up. Thus, the GRSN is a mixture of a physical and a virtual network.

Most array response simulations require high signal coherency across the array. This puts important constraints on the array geometry, spatial extent, and data quality. Proper analysis of array data is dependent on a stable, high precision relative timing of all array elements, because the measurement of very small time differences of the arrival of seismic signals between the different sensors plays an important role in all array-response techniques. Arrays provide 
estimates of the station-to-event azimuth (backazimuth), and of the apparent velocity of different types of waveforms. In this study, the applied procedure for estimating the slowness parameter and the angles of approach (azimuth and backazimuth) of detected array responses of the four events waveforms are given in detail. Here, we document array response simulation with waveform results from the SHM program for detecting and associates seismic signals from regional events using array installation data from the regional GERMAN (GR) and GEOFON (GE) in seven stations; RUE, GTTG, CLZ, RGN, IBBN, BSEG and HLG.

It is known that the upper crustal velocity together with the angle of incidence defines the apparent propagation speed of the wavefront at the observing instruments. This is not the physical propagation speed of the wavefront and is therefore called an apparent velocity. The inverse of the apparent velocity $v$ is called slowness $s$, which is a constant for a specific ray. For local or regional applications the unit of slowness is $[\mathrm{s} / \mathrm{km}]$. For global applications it is more appropriate to use the unit $\left[s /{ }^{\circ}\right]$ and the slowness is then called the ray parameter. The relation between the parameters of a plane wave and the actual seismic signal is given by the wavenumber vector $k . T$ is the period and $f$ the frequency of the seismic signal; $k$ absolute value of the wavenumber vector $k$ measured in $[1 / \mathrm{km}]$. $\lambda$ is the wavelength of the signal and because of the analogy between $\omega$ and $k, k$ is also called a spatial frequency.

\section{Results}

We compute the slowness and backazimuth from coherent phase picks by entry Plane Wave at SHM. This entry uses all phases of the name given in the phase dialog box. It assumes that the incoming wavefront of that phase is a plane wave. This algorithm is therefore applicable only if the epicentral distance is much larger than the aperture of the recording array and if the dominating frequencies of the picked signal are in a range where coherency is still possible (i.e. similar waveforms on the recording array). This algorithm determines the best fitting orientation of the wave plane and parameterizes it by slowness and back-azimuth. The resulting values are checked with command Beam, installing the locations of the recording stations in the station information file (lat and lon) (Figure 2). If the relative locations are not found in the file, SHM computes it from the lat. and lon and then, we begin to produce various array responses by using array transfer functions (Figures 2-4).

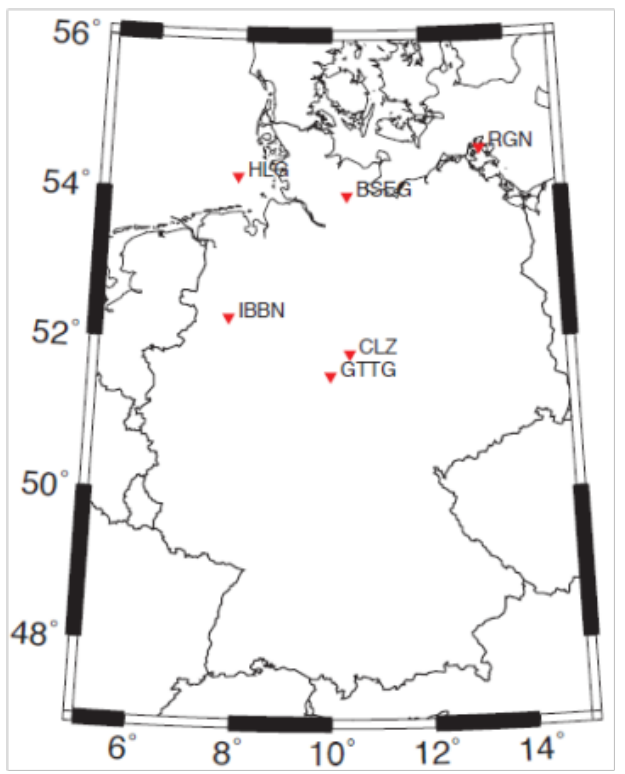

Figure 2 Stations used for FK Array response simulation.

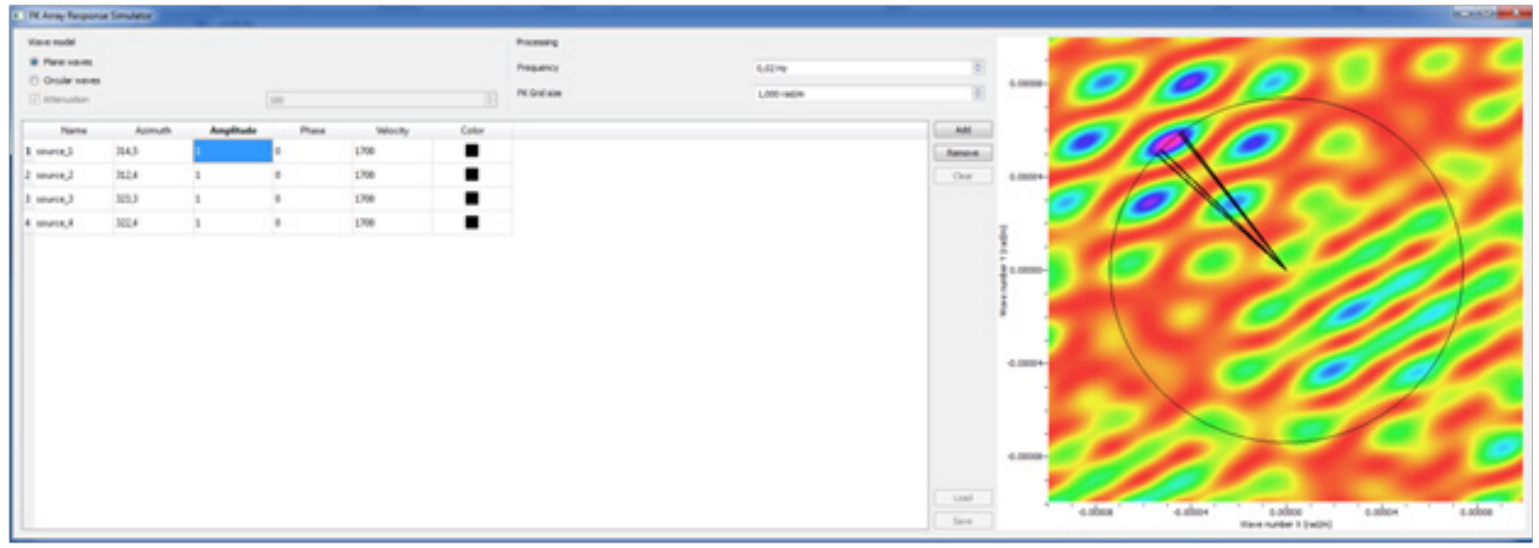

Figure 3 FK Array response simulations of the four glacial events with their azimuths. Wavenumber (k): $0.0001056(\mathrm{rad} / \mathrm{m})$, frequency: $0.02 \mathrm{~Hz}$, FK Grid size: $1,000 \mathrm{rad} / \mathrm{m}$, velocity: $1700 \mathrm{~m} / \mathrm{s}$.

The array transfer function describes sensitivity and resolution of an array for seismic signals with different frequency contents and slownesses. When digitizing the output from a seismometer, we sample the wavefront of a seismic signal in the time domain, and to avoid aliasing effects, we need to apply an anti-aliasing filter. Similarly, when observing a seismic signal using an array, we obtain a spatial sampling of the ground movement. With an array, or a dense network, we are able to observe the wavenumber $k$ of the wave defined by its wavelength $\lambda$ (or frequency $f$ ) and its slowness $s$. While analog to digital conversion may give aliasing effects in the time domain, the spatial sampling may give aliasing effects in the

wavenumber domain. Therefore the wavelength range of seismic signals, which can be investigated, and the sensitivity at different wavelengths must be estimated for a given array. The transfer function of an array is not only dependent on the slowness of the seismic phase observed with this array, but is also a function of the wavenumber $k$ (i.e., wavelength or frequency) of the observed signal, and of the array geometry (Figures 2-4). The aperture of an array defines the resolution of the array for small wavenumbers. The larger the aperture is, the smaller the wavenumbers (or slownesses) is that can be measured with the array. The number of sites controls the quality of the array as a wavenumber filter, i.e., its ability to suppress energy 
crossing the array. The distances between the seismometers define the position of the side lobes in the array transfer function and the largest resolvable wavenumber: the smaller the mean distance, the smaller the wavelength of a resolvable seismic phase will be (for a given seismic velocity). The geometry of the array defines the azimuth dependence.

Finally, we compute array transfer functions for array response of the four events by using open software Gpfksimulator (GEOPSY) (Figures 3 and 4). The relative coordinates " $x$ " and "y", azimuth and slowness are provided by SHM parameter information page for each detected event. The estimated parameters for array responses (Figure 3) (Figure 4) are the following; Bandpass filter: 35s-70s; Frequency range: $0.02857-0.01429 \mathrm{~Hz}$; The best frequency value to use for response image: $0.02 \mathrm{~Hz}$ (decimals not changed: the values 0.03 and 0.01 are out of the range); Velocity: $1700 \mathrm{~m} / \mathrm{s}$ (for Plio-Quaternary sediments) and the corresponding wavenumber range: $0.0001056-$ 5.2816e-5.

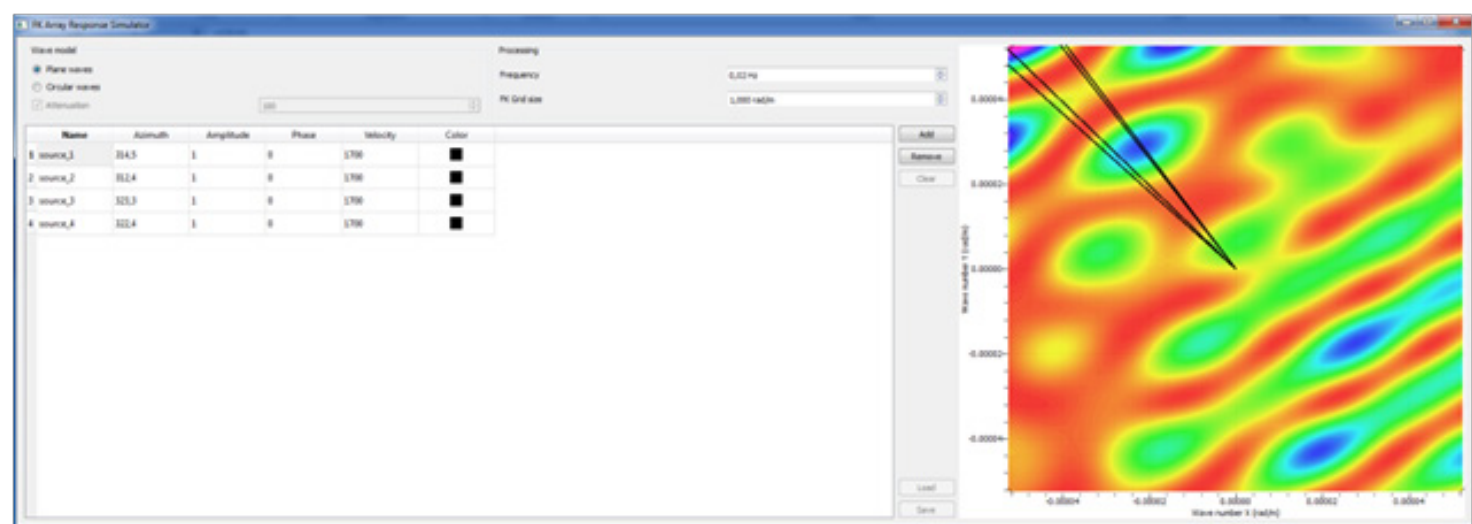

Figure 4 FK Array response simulation of the four glacial events with their azimuths. Wavenumber (k): $5.2816 \mathrm{e}-5$ (rad/m), frequency: $0.02 \mathrm{~Hz}$, FK Grid size: $1,000 \mathrm{rad} / \mathrm{m}$, velocity: $1700 \mathrm{~m} / \mathrm{s}$.

In two examples of array transfer functions (Figure 3) (Figure 4), the array shows resolution differences in different azimuths, which are caused by its geometry. The many side lobes of the transfer function are the effect of the larger distances between the single array sites. The resulting slowness and azimuths are also checked using the Beam option of SHM. The delay times for each station by a specific backazimuth and apparent velocity combination are defined to calculate an array beam (Figure 3) (Figure 4). The calculated delay times are depending on the relative position of the single sites with respect to the array's reference point and to the backazimuth of the seismic signal.

\section{Acknowledgments}

This work is supported by Yuzuncu Y1l University, Department of Geophysical Engineering (Van, Turkey) and University of Oulu, Sodankylä Geophysical University (SGO), Laboratory of Applied Seismology (Oulu, Finland) with the post-doctoral research grant and training agreement contract issued to Yuzuncu Y1l and Oulu Universities.

\section{Conflicts of interest}

The authors declare that there is no conflict of interest regarding the publication of this article.

\section{References}

1. Nettles M, Ekström G. Glacial Earthquakes in Greenland and Antarctica. Annu Rev Earth Planet Sci. 2010;38:467-491.

2. Ekström G, Nettles M, Abers GA. Glacial earthquakes. Science. 2002;302(5645):622-624.

3. Ekström G, Nettles M, Tsai VC. Seasonality and increasing frequency of Greenland glacial earthquakes. Science. 2006;311(5768):1756-758.

4. Ekström G, Nettles M. Detection and location of slow seismic sources using surface waves. Eos Trans. 2002.

5. Kawakatsu H. Centroid single force inversion of seismic waves generated by landslides. J Geophys Res.1989;94(B9):12363-12374.

6. Tsai VC. Ekström G. Analysis of glacial earthquakes. J Geophys Res. 2007.

7. Ekström G. Global detection and location of seismic sources by using surface waves. Bull Seismol Soc Am. 2006;96(4A):1201-1212. 